\title{
The Effect of Swedish Massage on Relieving Fatigue of Children with Acute Lymphoblastic Leukemia Undergoing Chemotherapy
}

\author{
Zahra Kashaninia ${ }^{1}$, Hamideh Zamanian Jahromi ${ }^{2 *}$, Kian Norouzi Tabrizi ${ }^{2}$, Enayatollah Bakhshi ${ }^{2}$ \\ 1. Department of Nursing, School of Nursing and Midwifery, Iran University of Medical Sciences, Tehran, Iran. \\ 2. Department of Nursing, University of Social Welfare and Rehabilitation Sciences, Tehran, Iran.
}

cttation: Kashaninia, Z, Zamanian Jahromi, H, Norouzi Tabrizi, K \& Bakhshi, E 2016, 'The effect of Swedish massage on relieving fatigue of children with acute Lymphoblastic Leukemia undergoing chemotherapy', Journal of Client-Centered Nursing Care, vol. 1, no, 4, pp. 205-210.

: http://dx.doi.org/10.15412/J.JCCNC.04010406

Article info:

Received: 18 Apr. 2015

Accepted: 14 Aug. 2015

Keywords:

Acute lymphoblastic leukemia, Chemotherapy, Fatigue, Swedish massage

\begin{abstract}
A B S T R A C T
Background: Fatigue is the most annoying side effect of cancer treatment in children who experience it from the time of diagnosis till conclusion of therapy. About $75 \%$ to $90 \%$ of children undergoing chemotherapy suffer from this complication. To relieve this problem, massage therapy is recommended which is the most widely applied adjuvant therapy. The purpose of this study was to determine the effect of Swedish massage on fatigue relieve in children aged 7-12 years suffering from acute lymphoblastic leukemia (ALL) who are undergoing chemotherapy at the Children's Medical Center of Tehran, Iran.

Methods: In this clinical trial, 50 children with ALL undergoing chemotherapy were assigned into 2 groups of intervention and control. First, the severity of fatigue in both groups was measured employing a child fatigue scale questionnaire. Then, in the intervention group, the Swedish massage with the effleurage technique was applied by the child's mother daily for 4 weeks. The fatigue in both groups was measured at the end of each week. The obtained data were analyzed, using descriptive and inferential statistics (repeated measures analysis).
\end{abstract}

Results: Indicated a significant difference in total score of quality of life and the mean score of fatigue between two groups after intervention $(\mathrm{P}<0.001)$. The mean score of fatigue intensity and total score of quality of life, had significant decrease in experimental group than control group after intervention.

Conclusion: Considering the results of this study, applying the Swedish massage by the mother as a supplemental and non-invasive intervention can be effective in reducing fatigue in children suffering from ALL who are undergoing chemotherapy.

\section{Background}

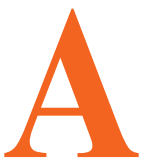

cute lymphoblastic leukemia (ALL) is the most common malignancy in children (Behrman, Kliegman \& Jenson 2011) and ac- counts for approximately $40 \%$ of all cases of malignant cancers in children under the age of 15 (Hockenberry, Wilson \& Wong 2011). In leukemia, chemotherapy is considered the treatment of choice. It is widely used in children's cancers because children tolerate better the acute side effects of

* Corresponding Author:

Hamideh Zamanian Jahromi, MSc.

Address: Atieh Hospital, Dadman Blv., Ghods Sq., Tehran, Iran.

Tel: +98 (936) 6982263

E-mail:zamani_hamide@yahoo.com 
chemotherapy. Also, malignant illnesses in children respond better to chemotherapy as compared with adults (Besharat \& Firoozi 2011).

Chemotherapy is an important treatment method, however, it causes serious side effects and in the meantime increases the costs of child's hospitalization (Perdikaris \& Papadatou 2008). Fatigue is the most bothersome side effect of cancer treatment in children who experience it from the time of diagnosis till conclusion of therapy (Colling, Macdonald \& Walton 2012). About $75 \%$ to $90 \%$ of children undergoing chemotherapy suffer from this side effect (De Niijs, Ros \& Gripdonck 2008). Fatigue is fundamentally different from daily tiredness which is short term and is relieved by resting (Perdikaris et al. 2009). Cancer-related fatigue is severe and irritating and is not relieved by rest. It manifests itself with chronic exhaustion and reduction in physical and mental functions (Erikson et al. 2012).

Fatigue is a mental phenomenon (Chandwani et al. 2012) with multidimensional effects on child's functions, daily chores, social life, mental abilities, emotional state, and appetite. Therefore, its control and relieve is difficult (Falkensteiner et al. 2011). New studies demonstrate that these patients repeatedly seek interventions (apart from medical clinics) to overcome medical complications. These interventions are called complementary or alternative medicine (Haun, Graham-Pole \& Shortley 2009).

Massage therapy is the most widely used therapy in complementary medicine (Reif et al. 2013). It is easy to execute, risk free, non-invasive, and relatively inexpensive which makes it the most common treatment used in nursing (Yilmaz 2012). Also, it is the most common and widely used treatments for children suffering from cancer and among 5 most preferred therapies (Spichiger 2011). Massage therapy is mostly used to overcome the side effects of anti-cancer drugs, such as pain, nausea, and fatigue, as well as to improve the child's quality of life during the treatment (Adhami \& Sadraee 2007). Swedish massage or classic massage has been the most common type of massage in the West and is considered the heart of educational programs on massage therapy (Batalha \& Mota 2013).

\section{Materials \& Methods}

This study is a clinical trial evaluated and compared 50 children aged 7-12 years suffering from ALL undergoing chemotherapy at Children's Medical Center of Tehran, Iran. First, all children with ALL who referred to the center were identified. Then, the severity of children's fatigue was measured through child fatigue scale questionnaire (CFS), and patients who received a score of 25 or higher were admitted to the study and were randomly placed in 2 groups of intervention and control.

The children should have undergone at least 2 periods of chemotherapy in a 4-8 week cycle. The first session of massage therapy was carried out by the mother at the clinic under the supervision of the researcher, and was continued later at home, once a day for 20 minutes, for 4 weeks. Twenty minutes of Swedish massage, including massage of the back, arms and face was applied to the child by the mother who had received required training from the researcher whose scientific competence had been approved by professors and masters of the art of massage. Prior to the massage of any part of the child's body, the massage oil was applied and rubbed on the child's body. Next, the Swedish massage with effleurage technique was applied in the following way.

First, the child lies face down on a firm mattress and a soft padding is placed under the belly and knees of the child. In the beginning, the back is massaged from above the hips to the shoulders for 5 minutes. Then, standing on the right side of the child, the right leg from the ankle to the upper thigh is massaged for 3 minutes and then the left leg in the same way. Afterwards, the right arm from the wrist to the upper arm is massaged for 3 minutes. Then, standing on the left side of the child, the left arm is massaged, and finally, the child lies down on his back, and the mother massages the child's face for 3 minutes. During the massage, the palms of both hands slides on the surface of the skin without moving the deep muscles.

Throughout the massage, the child should feel a continuous, proportional, and uniform motion. The pressing of the hand during the massage should increase a little when massaging from a down point upwards. Also, when the hand returns back to the starting point, the pressing of the hand should decrease (the rubbing motion should always be from down towards the heart, upper thighs, and back of the child).

When massaging a location, the mother should keep the contact of her hand with the child's body because disruption of contact results in loss of child's trust and calmness. Also, quick, irregular and sudden motions must be avoided. These types of motions will cause cluttering of the child's nerves. The entire palm of mother's hands (and not only the fingertips) should be applied during the massage, and in this way more areas of the child's body receives the therapy. When the location of the massage is a small area of the body such as the face, the plump surface of the fingers and the thumb are used. During the massage, a very brief conversation is exchanged with the child and no type of music is played. The control group received the conventional cares and treatments but filled out the questionnaires at determined dates. 
At the end of each week, fatigue was measured in both groups with the questionnaire on the child fatigue scale (CFS). The CFS questionnaire is used to examine changes in the fatigue of children aged 7-12 years suffering from cancer during the treatment period. This questionnaire was constructed in 1989 by pediatric expert Dr. Marilyn Hockenberry and contains 14 questions. In 2010, it was modified and changed by Hinds and colleagues, and its questions were reduced to 10 items. Furthermore, the validity of its items was assessed on 122 children between the ages of 7-12 who received anti-cancer treatment in 2011 by Khosravi through the content validity method (Khosravi 2012).

The Cronbach $\alpha$ was used to measure its durability, and the Cronbach $\alpha$ coefficient was calculated as 0.8 . This questionnaire includes 10 items and each item is scored based on a 5-point Likert-type scale from "not at all" to "very much". The frequency of the scores was classified from 0 to 10 and their severity from 10 to 50 . Higher scores indicate the higher severity of fatigue experienced by the child. In this study, the ranges of scores were classified as 10-23, 24-36, and 37-50.

Filling out the form would not take more than 5 minutes. During the intervention, the researcher contacted the child's home every other day to be ensured of carrying out exercises and answering any questions raised by the mother or the child. After data collection, SPSS version 16 was used to analysis data through descriptive statistics and analytical statistics methods. The repeated measures analysis was used to test the difference between the mean scores of fatigue severity. Repeated measures include the measures of a particular variable for each observation in several different situations. This measure is the extended mode of paired comparison test, in which a group is compared in several situations. The Ethics Committee of the university approved this research. Also, the study procedure was explained to the patients and their informed consents were taken and the confidentiality of their collected information was observed.

\section{Results}

Based on the results, the highest age frequency of studied children was $9(40 \%)$ years in the control group and 12 (24\%) years in the intervention group. About $64 \%$ of partici- pants were male. Most participants in the study groups were the first born in their family (64\% in the control group and $60 \%$ in the intervention group). Mothers of the most participants in both groups were high school graduates ( $44 \%$ in the control group and 52\% in the intervention group) and housewives ( $80 \%$ in the control group and $88 \%$ in the intervention group). Fathers of most participants were high school graduates $(48 \%$ in the control group and $44 \%$ in the intervention group) and were self-employed (52\% in the control group and $76 \%$ in the intervention group). In general, the following results were found by performing repeated measures between 2 groups (Table 1).

- A significant statistical difference was observed between the pretest scores and the end of the first week scores $(\mathrm{P}<0.001)$.

- No significant statistical difference was observed between the end of the first week and the end of the second week scores $(\mathrm{P}=114)$.

- A significant statistical difference was observed between the end of the second week and the end of the third week scores $(\mathrm{P}<0.009)$.

- A significant statistical difference was observed between the end of the third week and the end of the fourth week scores $(\mathrm{P}<0.039)$.

Analysis of repeated measures data did not show significant statistical difference between the end of the first week and the end of the second week scores. This finding can be explained by the fact that fatigue reaches its highest point during the week after chemotherapy, and during that week massage therapy was not able to be effective. However, by continuing the massage for the subsequent weeks, fatigue gradually reduced. Our findings also showed that after intervention, the mean fatigue score in the intervention group showed significant reduction, while in the control group it increased $(\mathrm{P}<0.001)$

\section{Discussion}

Findings of the present study showed that after performing the Swedish massage, the severity of fatigue reduced in the intervention group, while in the control group it increased.

Table 1. Mean and standard deviation of fatigue pretest and posttest scores.

\begin{tabular}{|c|c|c|c|c|c|}
\hline \multirow{2}{*}{ Group } & \multirow{2}{*}{ Variable } & \multirow{2}{*}{ No. } & \multicolumn{2}{|c|}{ Pretest } & \multicolumn{2}{c|}{ Posttest } \\
\cline { 4 - 7 } & & & Mean & SD & Mean \\
\hline Intervention & Fatigue & 25 & 29.40 & 3.66 & 21.48 \\
\hline Control & Fatigue & 25 & 25.96 & 0.840 & 28.48 \\
\hline
\end{tabular}


Table 2. Mean and standard deviation of fatigue test at the end of the first, second, and third week of intervention.

\begin{tabular}{|c|c|c|c|c|c|c|c|c|}
\hline \multirow{2}{*}{ Group } & \multirow{2}{*}{ Variable } & \multirow{2}{*}{ No. } & \multicolumn{2}{|c|}{ End of the first week } & \multicolumn{2}{c|}{ End of the second week } & \multicolumn{2}{c|}{ End of the third week } \\
\cline { 4 - 10 } & & & Mean & SD & Mean & SD & Mean & SD \\
\hline Intervention & Fatigue & 25 & 29.36 & 4.15 & 27.60 & 4.31 & 24.48 & 3.62 \\
\hline Control & Fatigue & 25 & 23.84 & 2.44 & 24.68 & 3.22 & 26.20 & 3.13 \\
\hline
\end{tabular}

Client-Centered Nursing Care

Table 3. Comparing the changes in severity of fatigue from before the intervention.

\begin{tabular}{|c|c|c|c|c|c|}
\hline Fatigue source & Total squares & df & Mean square & F & P-value \\
\hline Pretest until the end of first week & 58.32 & 1 & 58.32 & 12.86 & 0.001 \\
\hline $\begin{array}{c}\text { End of the first week till the end of the } \\
\text { second week }\end{array}$ & 10.58 & 1 & 10.58 & 2.59 & 0.114 \\
\hline $\begin{array}{c}\text { End of the second week till the end of } \\
\text { the third week }\end{array}$ & 32.00 & 1 & 6.49 & 0.009 \\
\hline $\begin{array}{c}\text { End of the third week till the end of } \\
\text { the fourth week }\end{array}$ & 6.48 & 1 & 4.50 & 0.039 \\
\hline
\end{tabular}

Client-Centered Nursing Care

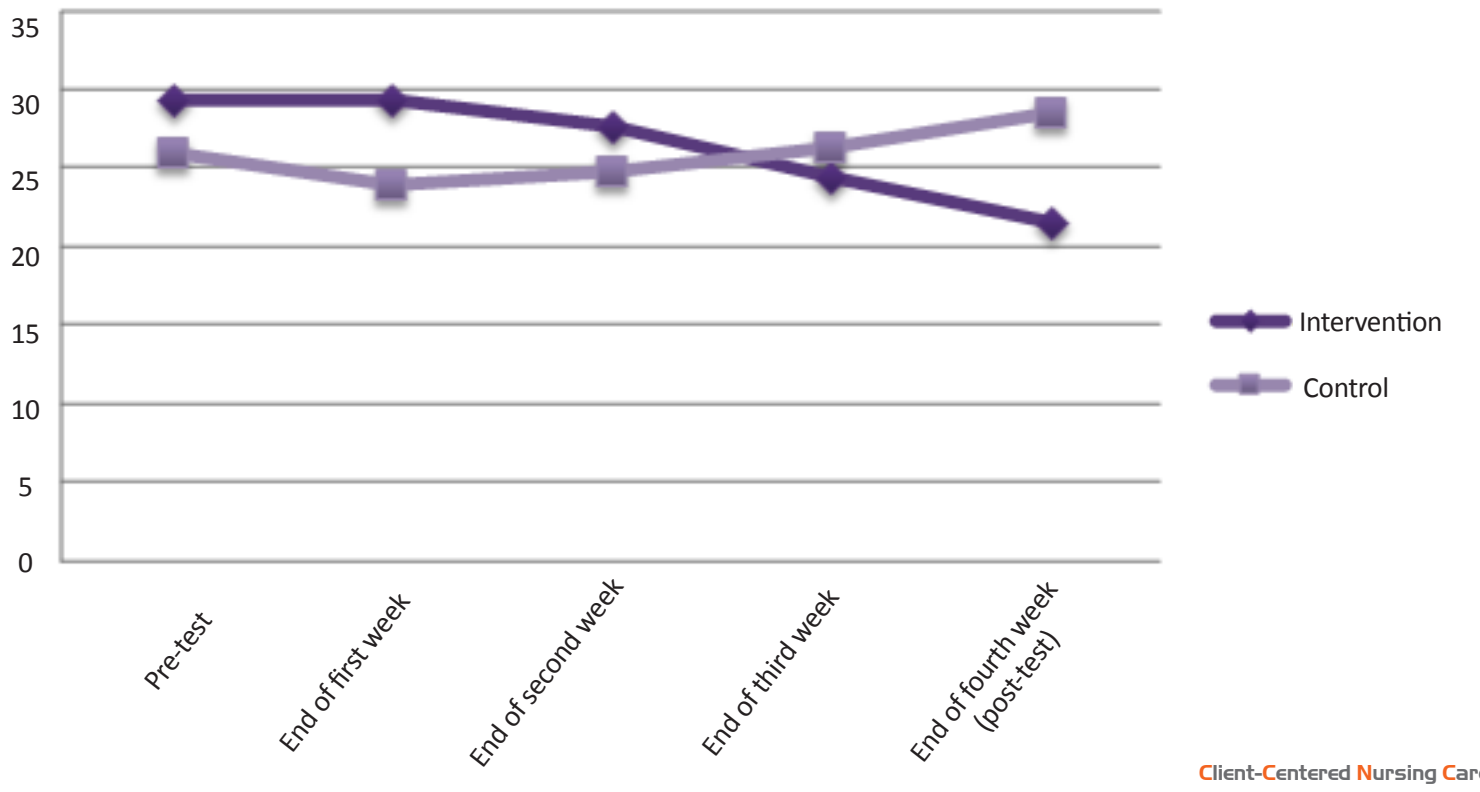

Figure 1. Comparison of fatigue severity between 2 groups of intervention and control, before intervetion and at the end of the first, second, and third week after intervention.

Our findings are consistent with the results of the following studies. In the study conducted by Karagozoglu and Kahve in 2013, the effect of back massage on fatigue and anxiety of patients with cancer under chemotherapy were assessed in a hospital in Turkey. Result of the present study with regard to reduction of fatigue is consistent with Karagozoglu research, and this consistency is likely due to the similarity of the massage received (Swedish massage) by the patients. However, samples in their research comprised individuals aged 41-60 years who were suffering from various forms of cancer and receiving only back massage by their nurses (Karagozoglu \& Kahve 2013).

The study conducted by Khosravi in 2011 entitled "Examining the effect of Acupressure on Nausea, Vomiting, and Fatigue in School Age Children Suffering from Acute Lymphoblastic Leukemia Who are Undergoing Chemotherapy" was similar to our present study in terms of the study popula- 
tion and instrument. Khosravi and colleagues concluded that a significant statistical difference was not observed immediately after intervention between the 2 groups of intervention and placebo, with regard to the severity of the fatigue. Such findings could likely be due to the fact that fatigue, like pain cannot be relieved or reduced quickly. Furthermore, fatigue during hospitalization days tends to increase, and its effect is multidimensional and affects patient's functions, daily chores, social life, mental abilities, emotional status, and appetite. Therefore, correct scheduling can be of utmost importance in determining the effect of complementary treatments (Khosravi 2012).

Likewise, Zick and colleagues (2011) conducted a study to examine the correct scheduling on the effectiveness of acupressure on fatigue. Their results showed that timely start of applying acupressure contributed significantly on its results on patients with cancer and concluded related treatments. According to the research, for achieving the highest effect of acupressure on the fatigue in participants, it is necessary to carry out 21 to 49 sessions of acupressure during a 7-week period, 3 times a week, on a daily basis. In fact, results of studies show that the more the number of acupressure sessions, the less becomes the fatigue. As regards the scheduling and timing, the Swedish massage was applied for 4 weeks and 20 minutes a day in our study, which was similar to the study of Zick and colleagues (Zick et al. 2011).

In view of the findings of the present study, we recommend that in addition to methods carried out in this study, the effectiveness of the Swedish massage and other techniques and methods of complementary medicine be studied and compared for reducing fatigue in children suffering from various types of malignancies. We hope that nurses teach this simple, inexpensive, and complication-free method to mothers of children with cancer.

\section{Conflict of Interests}

The authors declared no conflict of interests.

\section{Acknowledgements}

We acknowledge and express our gratitude and appreciation to Deputy Dean for Research at the University of Social Welfare and Rehabilitation Sciences and the staff of Children's Medical Center of Tehran. Also, we express our appreciation to all participants in this study that without their cooperation this research would have been impossible.

\section{References}

Adhami, H \& Sadraee, D 2007, '[Ethical issues in complementary and alternative medicine (Persian)]', Iranian Journal of Basic Medical Sciences, vol. 1, no. 2, pp. 69-72.

Batalha, LM, Mota, AA 2013, 'Massage in children with cancer: Effectiveness of protocol', Jornal de Pediatria, vol. 89, no. 6, pp. 1-6.

Behrman, A, Kliegman, K \& Jenson, L 2011, Nelson text book of pediatrics, $19^{\text {th }}$ edn, Saunders, Elsevier.

Besharat, MA \& Firoozi, M 2011, [Beyond medicine psycho-social aspects pediatric oncology (Persian)], Saba Publication, Tehran.

Chandwani, KD, Ryan, JL, Peppone, LJ, Janelsins, MM, Sprod, LK \& Devine, K et al 2012, 'Cancer related stress and complementary and alternative medicine: A review', Evidence-based Complementary and Alternative Medicine, vol. 2012, pp. 1-15.

Colling, W, Macdonald, G \& Walton, T 2012, 'Massage in supportive cancer care', Seminars in Oncology Nursing, vol. 28, no. 1, pp. 45-54

De Niijs, E, Ros, W \& Gripdonck, M 2008, 'Nursing intervention for fatigue during the treatment for cancer', Cancer Nursing, vol. 31, no. 3, pp. 191-206.

Erickson, JM, MacPherson, CF, Ameringer, S, Baggott, C, Linder, L \& Stegenga, K 2012, 'Symptoms and symptom clusters in adolescents receiving cancer treatment: A review of the literature', International Journal of Nursing Studies, vol. 50, no. 6, pp. 847-69.

Falkensteiner, M, Mantovan, F, Müller, I \& Them, C 2011, 'The use of massage therapy for reducing pain, anxiety, and depression in oncological palliative care patients: A narrative review of the literature', International scholarly Research Network, vol. 2011, pp. 1-8

Haun, JN, Graham-Polem, J \& Shortley, B 2009, 'Children with cancer and blood diseases experience positive physical and psychological effects from massage therapy', International Journal of Therapeutic Massage and Bodywork, vol. 2, no. 2, pp. 7-13.

Hockenberry, M \& Wilson, D 2011, Wong's nursing care of infants and children, Mosby, Elsevier.

Karagozoglu, S \& Kahve, E 2013, 'Effects of back massage on chemotherapy-related fatigue and anxiety: Supportive care and therapeutic touch in cancer nursing', Applied Nursing Research, vol. 26, no. 4., pp. 210-217.

Khosravi, M 2012, '[The effect of Acupressure on chemotherapy-induced nausea, vomiting and fatigue among school age children with Acute lymphoblastic leukemia (Persian)]' [MSc. thesis], Tehran University of Medical Sciences.

Perdikaris, P \& Papadatou, D 2008, 'Changes in children's fatigue during the course of treatment for pediatric cancer', International Council of Nurses, vol. 55, no. 4, pp. 412-19.

Perdikaris, P, Merkouris, A, Patiraki, E, Tsoumakas, K, VasilatouKosmidis, E \& Matziou, V 2009, 'Evaluating cancer related fatigue during treatment according to children's, adolescents, and parents, perspective in a sample of Greek young patients', European Journal of Oncology Nursing, vol. 13, no. 5, pp. 399-408.

Reif, K, de Vries, U, Petermann, F \& Görres, S 2013, 'A patient education program is effective in reducing cancer-related fatigue: A multi-center randomized two-group waiting-lost controlled intervention trial', European Journal of Oncology Nursing, vol. 17, no. 2, pp. 204-213. 
Spichiger, E, Rieder, E, Müller-Fröhlich, C \& Kesselring, A 2011, ‘Fatigue in patients undergoing chemotherapy, their self-care and the role of health professionals: A qualitative', European Journal Oncology Nursing, vol. 16, no. 2, pp. 165-71.

Yilmaz, HB 2012, Fatigue in pediatric oncology patients, http:/ / www. intechopen.com/books/contemporary-pediatrics.

Zick, SM, Alrawi, S, Merel, G, Burris, B, Sen, A, Litzinger, A et al 2011, 'Relaxation acupressure reduces persistent cancer related fatigue', Evidence-based Complementary and Alternative Medicine, vol, 2011, pp. 1-10. 